\title{
Regimen Used to Treat Primary Amyloidosis
}

National Cancer Institute

\section{Source}

National Cancer Institute. Regimen Used to Treat Primary Amyloidosis. NCI Thesaurus.

Code C159461.

Any regimen that can be used for the treatment of primary amyloidosis. 